\title{
Mechanical Stimulation Increases the Proliferation and Differ- entiation Potential of Human Adipose-Derived Stromal Cells
}

\author{
Susanne Jung, Lauren Bohner, Kathrin Spindler, Marcel Hanisch, Johannes \\ Kleinheinz and Sonja Sielker*
}

Department of Cranio-Maxillofacial Surgery, Research Unit Vascular Biology of Oral Structures (VABOS), University Hospital Muenster, Germany

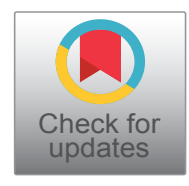

*Corresponding author: Sonja Sielker, PhD, Department of Cranio-Maxillofacial Surgery, University Hospital Muenster, Waldeyerstraße 30, D-48149 Muenster, Germany, Tel: +49-251-83-47007, Fax: +49-251-83-47184

\begin{abstract}
Background: Dynamic conditions stimulate the bone remodeling process by improving the nutrients transport and increasing the expression of osteogenic cells. The purpose of this study was to evaluate the effect of mechanical stimulation on the osteogenic differentiation of human adipose-derived stromal cells.

Methods: Cells were cultured under static and dynamic conditions in collagen scaffolds for 14 days. The mechanical stimulation was performed using a biaxial rotating bioreactor $(5 \times \mathrm{rpm}$ and perfusion flow rate of $10 \times$ rpm). Cell viability was analyzed with a living cell count and a MTT assay. Changes in expression of specific stem cell marker, osteogenic marker and endothelial markers were analyzed on gene (RT-qPCR) and protein (IHC) level. Data were statistically analyzed by one-way ANOVA $(p=0.05)$.

Results: Cell viability was higher under dynamic condition and cells migrated deeper in the collagen matrix. Expression of stem cell marker (ANPEP/CD13, CD44, THY1/CD90) was significant higher under dynamic condition. This was also observed for osteogenic markers (collagen 1, osteopontin, osteonectin).

Conclusion: The mechanical stimulation increased significantly cell viability and differentiation potential of human adipose-derived stromal cells.
\end{abstract}

\section{Keywords}

hADSC, Dynamic stress, Expression profile, Biaxial bioreactor

\section{Introduction}

Bone fracture defects require an interventional treatment which is dependent from the size of the injured site: Whereas smaller bone defects may be spontaneously solved and comprise minimal intervention approaches, larger bone defects usually require the use of replacement material in order to facilitate the healing process $[1,2]$. Although autologous bone grafting is the gold-standard to facilitate bone repair, the approach is limited due to the low availability of bone material and morbidity of the donor-site. In order to overcome these limitations, tissue engineering approaches have been developed and have been shown a rapidly growth on the field of regenerative medicine. The technique simulates the physiological process of bone repair by using a combination of osteoprogenitors, cytokines and bioactive carriers. In this sense, the use of stem cells is the start point to stimulate osteogenesis [3-8].

Mesenchymal stem cells play an important role in tissue engineering approaches due to their capacity to differentiate in multiple cell lineages [2,9]. These cells may be acquired from different sources, and their differentiation potential depends on the donation site [1012]. For the treatment of bone defects, mesenchymal cells are typically harvested from the bone marrow [1315], which is considered a painful and time-consuming procedure. Furthermore, it is associated with a risk of cell contamination and graft loss [16].

In this regard, human adipose-derived stem cells (hADSCs) present some advantages due to their abundant source of osteoprogenitors, easy accessibility and the large quantity of donor tissue available [16-19].

Citation: Jung S, Bohner L, Spindler K, Hanisch M, Kleinheinz J, et al. (2018) Mechanical Stimulation Increases the Proliferation and Differentiation Potential of Human Adipose-Derived Stromal Cells. Int J Stem Cell Res Ther 5:056. doi.org/10.23937/2469-570X/1410056

Accepted: December 03, 2018: Published: December 05, 2018

Copyright: (C) 2018 Jung S, et al. This is an open-access article distributed under the terms of the Creative Commons Attribution License, which permits unrestricted use, distribution, and reproduction in any medium, provided the original author and source are credited. 
Although the osteogenic capacity of hADSCs seems to be lower in comparison to bone marrow-derived stem cells [20], intrinsic and extrinsic inducing factors, as an osteogenic medium or mechanical vibration, are used to stimulate the osteogenesis [21-26].

Mechanical vibration by means of bioreactors is able to simulate the physiological movements occurred in vivo during the bone remodeling by mimic in vitro physiological mechanostimulation [27]. Under dynamic culture, there is an improvement on the nutrients transport, associated with an increase on the expression of osteogenic cells, favoring the bone remodeling processes [28]. Although this method seems to be effective to enhance proliferation and differentiation of hADSCs [29], the protocol usually comprises the use of an osteogenic medium [30,31], and a possible synergistic effect cannot be excluded. Thus, the mechanism by which the mechanical vibration alone stimulates the bone regeneration is not yet fully understood. The present study aimed to evaluate whether the mechanical vibration would be able to stimulate bone formation without using an osteogenic medium.

\section{Material and Methods}

\section{Experimental design}

In order to evaluate the effect of dynamic stimulation on hADSCs, cells were cultured during 14 days in static or dynamic conditions without using osteogenic inducing factors. Cell proliferation and differentiation analysis was performed after 7 and 14 days of culture.

\section{Cell isolation}

Human subcutaneous fat tissue was collected under sterile conditions from the leftover tissue of patients submitted to elective abdominal surgery on the General and Visceral Surgery, University Hospital Muenster, Germany. Isolation and cell growth were described previously [11].

\section{Cell culture}

The constant conditions $\left(37{ }^{\circ} \mathrm{C}, 5 \% \mathrm{CO}_{2}\right.$ and $95 \%$ humidity) were kept during the whole experimental period. Cell culture medium was alpha eagle minimal medium ( $\alpha$-MEM, Lonza, Switzerland) containing 10\% fetal bovine serum (10\%), amphotericin B, glutamine, and penicillin/ streptomycin (each 1\%; all Biochrom Merck, Germany).

Collagen punches with a diameter of $10 \mathrm{~mm}$ were cut from a collagen membrane ("PARASORB ${ }^{\circledR}$ Fleece $H^{\prime \prime}$, Resorba Medical GmbH, Germany) under sterile conditions and used as scaffolds. Each scaffold was placed into a 24-well culture plate (TPP, Switzerland) and fixed on the well bottom with $400 \mu$ low melt agarose $(4 \%$ in $\alpha$-MEM, Plaque Agarose, Biozym, Germany) during $24 \mathrm{~h}$. hADSC were seeded with $1 \times$ $10^{5}$ cells onto each collagen scaffold, and incubated for initial incubation for 4 days.
After the initial culture, the hADSC were randomly divided into two experimental groups based on static and dynamic conditions. For the static condition, the cells remained in 24-well culture plates for the following 10 days. For the dynamic condition, after the initial incubation, the cells were submitted to mechanical vibration during the same period (10 days).

The dynamic condition was simulated by a biaxial rotation bioreactor ("TisXell Regeneration System"; Quintech Life Science; Singapore) filled with $700 \mathrm{ml}$ of $\alpha$-MEM Running conditions for the TisXell Regneration System bioreactor were determined with a biaxial rotating of $5 \times \mathrm{rpm}$ and a perfusion flow rate of $10 \times \mathrm{rpm}$ [31]. Cell culture part was repeated three times.

\section{Cell proliferation analysis}

Living cell count was performed with the CASY1 cell counter (Schärfe System, Germany) according to manufacture protocol. Proliferation rate were estimated with an in-house MTT assay. The conversion of the yellow thiazolyl blue tetrazolium bromit $(0.5 \mathrm{mg} /$ $\mathrm{ml}$; Sigma-Aldrich, Germany) to the purple formazan was measured at $\lambda 570 \mathrm{~nm}$. All assays were performed according to the manufacture protocols and done in triplicates.

\section{Real-time quantitative reverse transcription poly- merase chain reaction (RT-qPCR)}

The analysis of the mRNA-expression of osteogenic and endothelial markers was performed by RTPCR. Total RNA was extracted and purified by the "miRNeasy Mini Kit" (Qiagen, Germany). Purity and concentration of the isolated total RNA was determined by a spectrophotometric reading (NanoDrop ${ }^{\mathrm{TM}}$ 2000; ThermoFisher Scientific, Germany). Genomic DNA contamination was reduced by a DNase I treatment (ZeroBase ${ }^{\mathrm{TM}}$ DNase I; epicenter, Germany) followed by a cDNA synthesis ( $1 \mu \mathrm{g}$ RNA; MMLV Reverse Transcriptase $1^{\text {st }}$ strand cDNA synthesis kit; epicenter, Germany). cDNA was amplified on Mastercycler ${ }^{\circledR}$ RealPlex S4 (Eppendorf, Germany) using commercially available primers in triplicates (Eurofins Genomics GmbH, Germany) and the DyNAmo Color Flash SYBR Green qPCR Kit (Biozym; Germany). Primers are listed in Table 1. PCR conditions were: Initial denaturation at $95{ }^{\circ} \mathrm{C}$ during 7 minutes, followed by 45 cycles of denaturation at $95^{\circ} \mathrm{C}$ for 10 $\mathrm{s}$, annealing at $54{ }^{\circ} \mathrm{C}$ for $15 \mathrm{~s}$ and extension at $72{ }^{\circ} \mathrm{C}$ for $20 \mathrm{~s}$. Analysis was performed using the Mastercycler ${ }^{\oplus}$ software (Eppendorf, Germany).

\section{Immunohistochemistry}

In order to determine the protein expression of specific stem cell markers, osteogenic markers, and endothelial markers, an immunohistochemistry was performed. hADSC collagen scaffolds were fixed in $4 \%$ of buffered formalin (Fisher Scientific UK limited, UK) for $1 \mathrm{~h}$ and embedded immediately in HistoGel 
(Thermo Scientific, Germany). Samples were watered and dehydrated through an increasing grades ethanol solution. After, the samples were transferred to cedar wood oil (Merck, Germany) during $24 \mathrm{~h}$ and into warm 1:1 paraffin-cedar wood oil mixture for $48 \mathrm{~h}$, followed by warm paraffin (Paraplast Plus; Tyco Healthcare Group LP, USA) for $72 \mathrm{~h}$. After cooling down for $24 \mathrm{~h}$ at $-20{ }^{\circ} \mathrm{C}$, samples were embedded into fresh paraffin and sectioned with a microtome (Leica Microsystems $\mathrm{GmbH}$, Germany). Sections were mounted onto slides one day before staining. Afterwards, they were deparaffinized in xylene and rehydrated through decreasing grades ethanol solution.

The following primary monoclonal antibodies from

Table 1: Primers used for RT-qPCR.

\begin{tabular}{|c|c|}
\hline Gene & Primer sequence \\
\hline \multicolumn{2}{|c|}{ Housekeeping genes } \\
\hline GAPDH-F & 5'-CTCAGACACCATGGGGAAGG-3' \\
\hline GAPDH-R & 5'-TCGCTCCTGGAAGATGGTGA-3' \\
\hline RNA18S5-F & 5'-AGAAACGGCTACCACATCCA-3' \\
\hline RNA18S5-R & 5'-CССTCCAATGGATCCTCGTT-3' \\
\hline \multicolumn{2}{|c|}{ Stem cell marker } \\
\hline CD44-F & 5'-CCCATTCGACAACAGGGACA-3' \\
\hline CD44-R & 5'-TGGGGTGTGAGATTGGGTTG-3' \\
\hline ANPEP-F & 5'-TCAACTACACCCTCAGCCAG-3' \\
\hline ANPEP-R & 5'-ATTGCCCTCCATGTACTCGC-3' \\
\hline THY1-F & 5'-CAGCATCGCTCTCCTGCTAA-3' \\
\hline THY1-R & 5'-ACTGGATGGGTGAACTGCTG-3' \\
\hline \multicolumn{2}{|c|}{ Osteogenic marker } \\
\hline BGLAP-F & 5'-ACACTCCTCGCCCTATTGGC-3' \\
\hline BGLAP-R & 5'-GATGTGGTCAGCCAACTCGT-3' \\
\hline SPP1-F & 5'-CATCACCTGTGCCATACCAGTT-3' \\
\hline SPP1-R & 5'-TTGGAAGGGTCTGTGGGGCTA-3' \\
\hline COL1A1-F & 5'-CCACCAATCACCTGCGTACA-3' \\
\hline COL1A1-R & 5'-GGCAGTTCTTGGTCTCGTCA-3' \\
\hline \multicolumn{2}{|c|}{ Endothelial marker } \\
\hline CD34-F & 5'-AAGCCGAGTAGTGTCTTCCAC-3' \\
\hline CD34-R & 5'-GGGGTAGCAGTACCGTTGTT-3' \\
\hline PECAM1-F & 5'-TCCCCTAAGAATTGCTGCCA-3' \\
\hline PECAM1-R & 5'-TCTTCCCAACACGCCAATGA-3' \\
\hline VWF-F & 5'-ATGCCCCTGGAGAAACAGTG-3' \\
\hline VWF-R & 5'-CCGAAAGGTCCCAGGGTTAC-3' \\
\hline
\end{tabular}

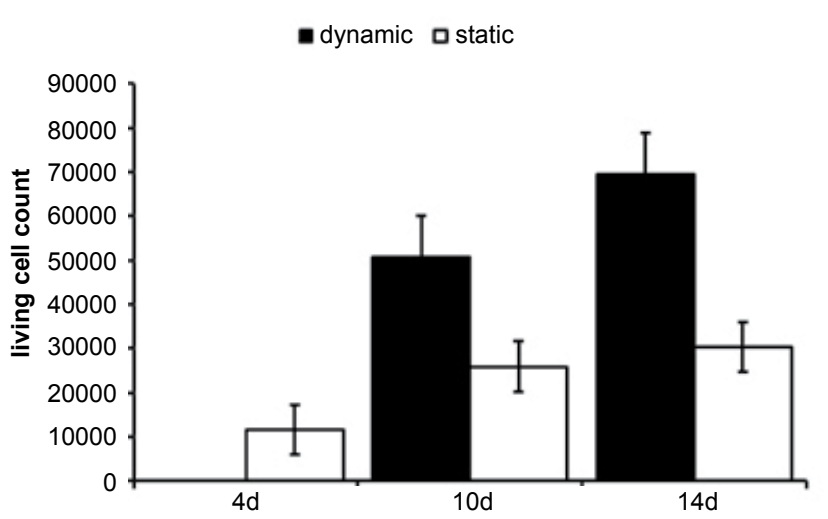

mouse were tested: CD13 (clone WM 15, dilution 1:100, Thermo Fischer Scientific, USA), CD31 (clone JC70A; dilution 1:20; Dako, Germany), CD34 (clone QBEnd/10, dilution 1:100; EMD Millipore, USA), CD44 (clone A3D8, dilution 1:100; Sigma Aldrich, Germany), CD90 (clone AF-9; dilution 1:50; Thermo Fischer Scientific, USA), and osteocalcin (clone OC4-30; dilution 1:50; TaKaRa, Japan). In addition, primary polyclonal antibodies acquired from rabbit were evaluated: osteonectin (dilution 1:200; Merck, Germany), osteopontin (dilution 1:100; Merck, Germany), and vWF (\#F3520, dilution 1:1600, Sigma Aldrich, Germany). Dako "REAL ${ }^{\text {TM" }}$ Detection Kit was used for secondary antibody detection (Dako, Germany). Haematoxylin was used for counter-staining (Sigma-Aldrich, Germany). Negative as well as positive controls were implemented according to manufacturer's protocols. Staining results were summarized in a semi quantitative score (IRS) defined as: $0=$ no staining, 1 $=$ staining in less than $20 \%$ of cells, $2=$ staining in 21 to $50 \%$ of cells, 3 = staining in 51 to $90 \%$ of cells, and 4 = staining in more than $90 \%$ of cells. Six slices were analyzed for each sample and for each antibody. Samples were analyzed by three well-trained professionals with experience in histochemical techniques and analysis.

\section{Statistical analysis}

The expression factors and IRS score were evaluated by one-way ANOVA with a modified Levene test. PostHoc analysis was performed with Bonferroni-Holm test. Statistical significance was set at $p<0.05$. The statistical analyses were performed using the software Daniel's $\mathrm{XL}$ Toolbox version 6.53, available at $\mathrm{http}$ ://xltoolbox. sourceforge.net.

\section{Results}

\section{Cell vitality}

Figure 1 shows the results for the living cell count and proliferation (MTT). The growth rate is two times higher in dynamic culturing conditions, whereas the functional activity is 1.2 to 1.5 times higher under dynamic conditions in comparison to static conditions. The dynamic condition showed a statistically significant

Figure 1: Living cell count $(p=0.034)$ and MTT $(p=0.013)$ [light bar = static cultivation; dark bar = dynamic cultivation; standard abbreviation as error marks; at day 4 only information for static cultivation existing]. 


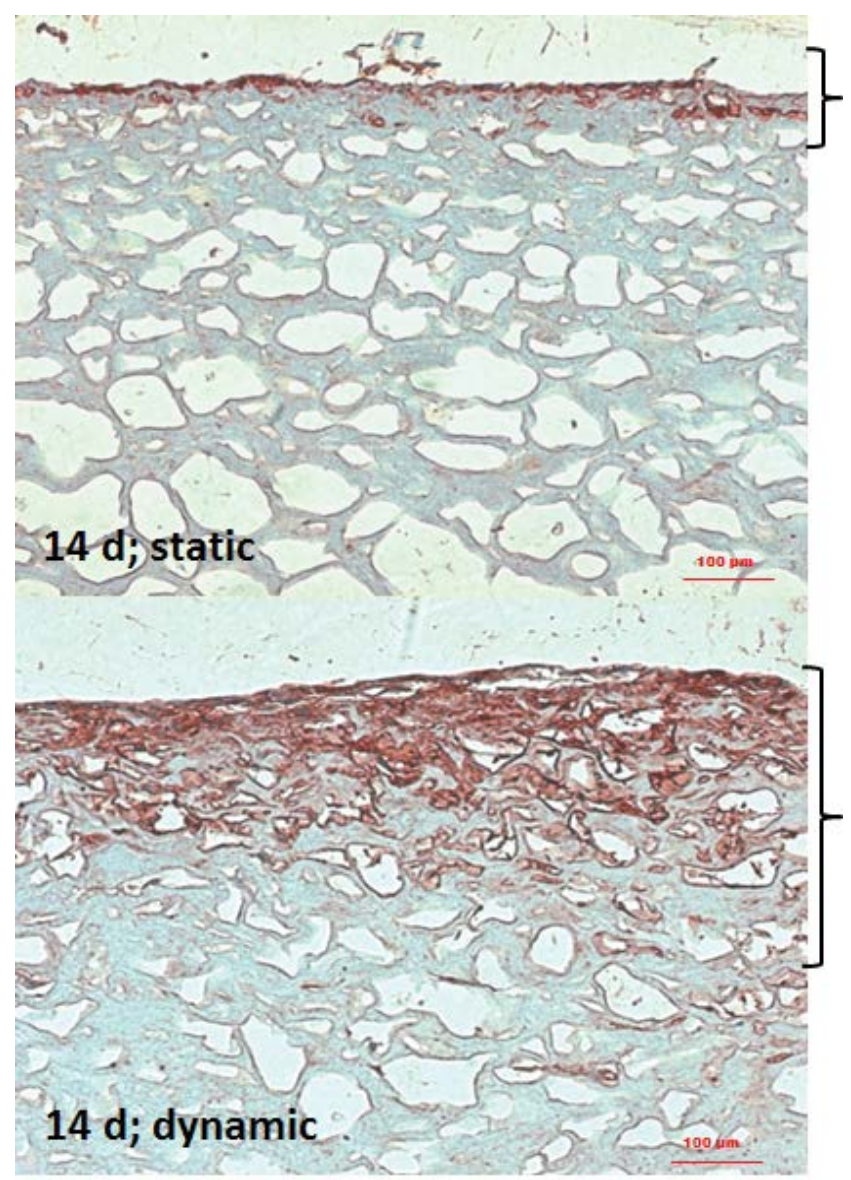

Figure 2: IHC of osteopontin in static and dynamic culturing conditions at day 14 (bold bracket = growth area; 100-fold magnification; size bar $100 \mu \mathrm{m})$.

difference between dynamic and static condition in living cell count $(p=0.034)$ and proliferation rate $(p=$ 0.013). Furthermore, the cells migrated deeper into scaffold matrix under dynamic conditions, as shown on Figure 2. Conversely, under static conditions, cells were arranged mostly at the matrix surface.

\section{Real time PCR}

The gene expressions of stem cell, osteogenic and endothelial markers are summarized in Figure 3. The statistical analysis showed a significance for stem cell markers $(p=0.021)$ and endothelial markers ( $p$ $=0.043$ ). A Posthoc test was accomplished for gene expression and showed statistical significance among each other with at least $p=0.05$ (asterisks in Figure $3)$. For osteogenic marker, there was no significant in one-way ANOVA. Nevertheless, gene expression of stem cell and osteogenic markers increased along the time under dynamic culturing conditions and decreased under static culturing conditions (Figure $3 \mathrm{~A}$ and Figure 3B). The alteration in gene expression for all analysed genes referring to incubation time were significant with $p=0.000078$ and alteration at day 14 under dynamic conditions were significantly higher compared to day 10 and day 4 under static and dynamic condition with at least $p=0.008$. The gene expression of BGLAP (osteocalcin) and PECAM 1 (CD31) was not observed, neither under
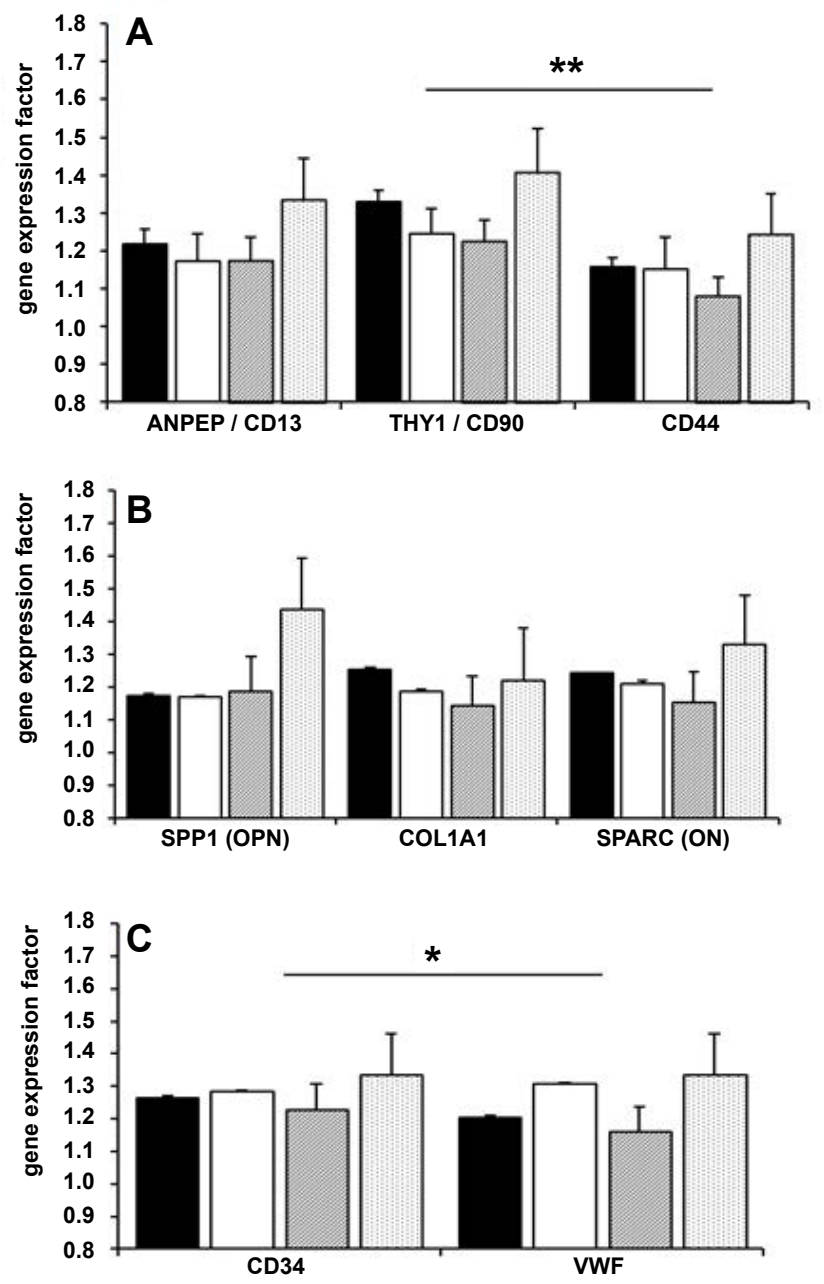

Figure 3: Gene expression factors of stem cell markers [A, $p=0.021]$, osteogenic markers $[B]$, and endothelial markers $[C, p=0.043]$ (black \& white bars = static cultivation at day 10 and day 14 ; dark \& light spots = dynamic cultivation at day 10 and day 14; error marks = standard abbreviation).

static as under dynamic culturing conditions. Expression of CD34 and vWF showed slightly effects between static and dynamic culturing conditions (Figure $3 \mathrm{C}$ ).

\section{Immunohistochemistry}

The results of the immunohistochemistry are summarized in Figure 4. The statistical analysis showed a statistical significance for stem cell markers ( $p=$ $0.000019)$, osteogenic $(p=0.013)$ and endothelial markers $(p=0.029)$. A Posthoc test was accomplished for protein expression and showed statistical significance among each other with at least $p=0.03$ (asterisk in Figure 4). IHC results mostly affirmed results of gene expression analysis. Protein expression of stem cell and osteogenic markers remained constant or decrease under static conditions and increased under dynamic conditions (Table 2). Collagen 1 was not analyzed due to the collagen origin of used scaffolds. As well as in gene expression analysis, osteocalcin was not expressed. Protein expression of endothelial markers also affirmed in parts results of gene expression analysis (Table 2). 
Table 2: Semi-quantitative IHC score of stem cell markers, osteogenic markers, and endothelial markers (Standard abbreviation in brackets; $p=p$-value).

\begin{tabular}{|c|c|c|c|c|c|c|c|c|c|c|}
\hline \multirow[b]{2}{*}{ Culturing conditions } & \multicolumn{6}{|c|}{ Static conditions } & \multicolumn{4}{|c|}{ Dynamic conditions } \\
\hline & \multicolumn{2}{|c|}{ Day 4} & \multicolumn{2}{|c|}{ Day 10} & \multicolumn{2}{|c|}{ Day 14} & \multicolumn{2}{|c|}{ Day 10} & \multicolumn{2}{|c|}{ Day 14} \\
\hline \multicolumn{11}{|c|}{ Stem cell markers $\left(p=1.9 \times 10^{-5}\right)$} \\
\hline CD13 & 3.5 & $( \pm 1.2)$ & 4 & $( \pm 0)$ & 3.5 & $( \pm 1.2)$ & 4 & $( \pm 0)$ & 4 & $( \pm 0)$ \\
\hline CD90 & 0.7 & $( \pm 0.5)$ & 0.8 & $( \pm 0.8)$ & 0.8 & $( \pm 0.5)$ & 0.7 & $( \pm 0.5)$ & 1 & $( \pm 0.6)$ \\
\hline CD44 & 1 & $( \pm 1.6)$ & 2.2 & $( \pm 1.2)$ & 2.3 & $( \pm 1.9)$ & 3.2 & $( \pm 1.2)$ & 3 & $( \pm 0)$ \\
\hline \multicolumn{11}{|c|}{ Osteogenic markers $\left(^{*}\right)(p=0.013)$} \\
\hline Osteopontin & 3.8 & $( \pm 0.4)$ & 3.8 & $( \pm 0.4)$ & 2.2 & $( \pm 0.5)$ & 3.8 & $( \pm 0.4)$ & 4 & $( \pm 0)$ \\
\hline Osteonectin & 4 & $( \pm 0)$ & 4 & $( \pm 0)$ & 4 & $( \pm 0)$ & 4 & $( \pm 0)$ & 4 & $( \pm 0)$ \\
\hline \multicolumn{11}{|c|}{ Endothelial markers $\left(^{* \star}\right)(p=0.029)$} \\
\hline CD34 & 0.5 & $( \pm 0.5)$ & 0.5 & $( \pm 0.8)$ & 0.4 & $( \pm 0.7)$ & 0.3 & $( \pm 0.5)$ & 0.9 & $( \pm 1.4)$ \\
\hline vWF & 0.2 & $( \pm 0.4)$ & 0 & $( \pm 0)$ & 0.5 & $( \pm 0.6)$ & 0.2 & $( \pm 0.4)$ & 0 & $( \pm 0)$ \\
\hline
\end{tabular}

"Collagen I was not analyzed due to the collagen origin of the scaffolds; Osteocalcin was not detectable; ${ }^{*} \mathrm{CD} 31$ was not detectable.

$\square$ 4d; static $₫ 10 \mathrm{~d}$; static $\square 14 \mathrm{~d}$; static $\square 10 \mathrm{~d}$; dynamic $\square 14 \mathrm{~d}$; dynamic
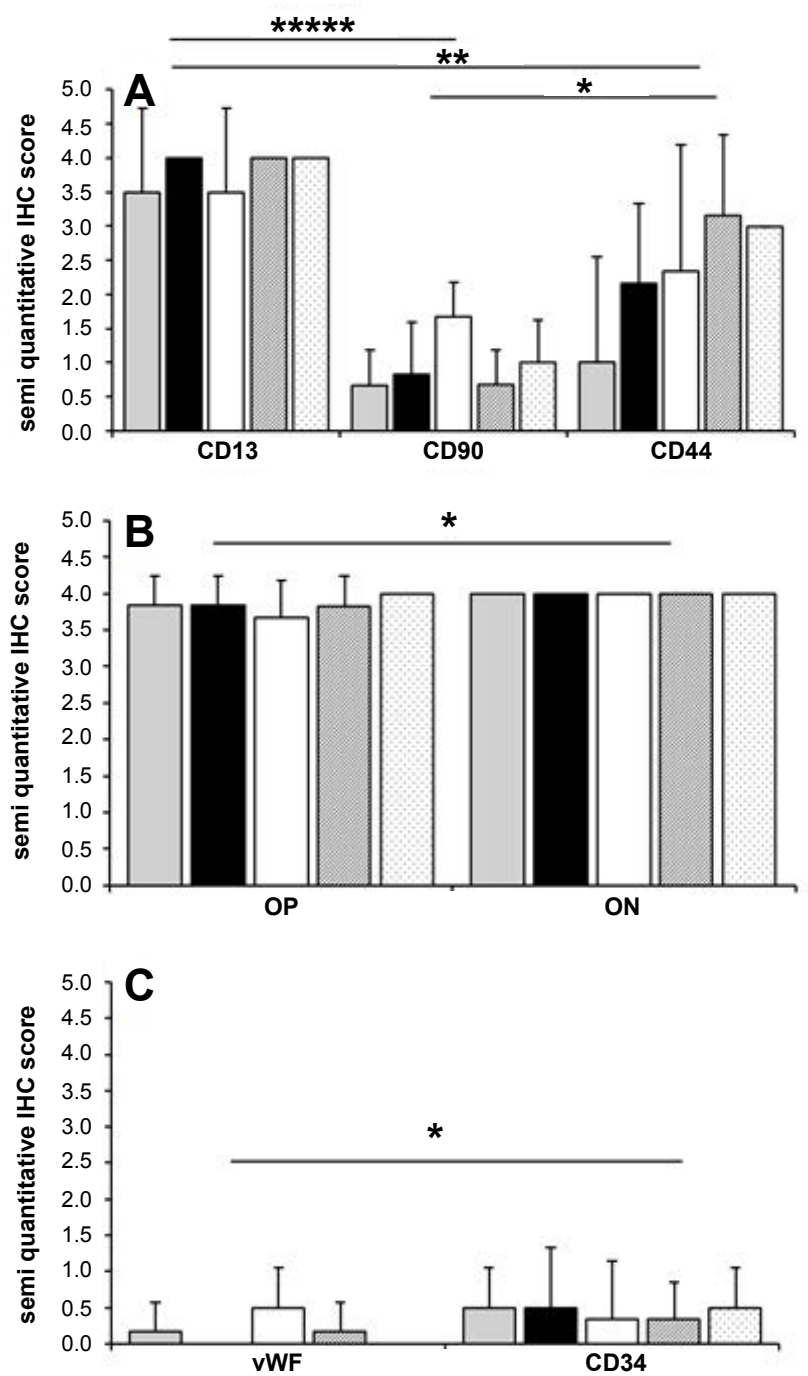

Figure 4: Semi quantitative IHC score of stem cell markers $[A, p=0.000019]$, osteogenic markers [B, $p=0.013]$, and endothelial markers [C, $p=0.029$ ] (grey, black \& white bars $=$ static cultivation at day 4,10 and 14 ; dark \& light spots = dynamic cultivation at day 10 and day 14; error marks = standard abbreviations).

Expression of CD34 was weak and remained constant or increased. As well as no gene expression of PECAM 1 was observable, expression of CD31 was not detectable.
In contrast, expression of VWF was under dynamic condition very weak and it decreased during incubation.

\section{Discussion}

The basic principle of a dynamic culture system is a change on the cell cytoskeleton [29], improving nutrient transport [28] and enhancing the mechanical signals related with cell proliferation pathways [32]. The perfusion bioreactor used in this study facilitates the fluid of the medium into the scaffold, creating an optimal microenvironment for cell differentiation [28]. However, as it is usually associated with an osteogenic medium, its role on the osteogenesis process is still unknown. The present study aimed to evaluate whether the mechanical vibration by a perfusion reactor is able to induce alone the proliferation and differentiation of hADSCs.

The growth and proliferation rates of stem cells, such as the gene expression and presence of osteogenic markers, were stimulated under dynamic conditions, leading to a better response in comparison with static cultures. In this respect, the use of mechanical vibration seems to increase the effectiveness of cells on the treatment of large bone defects. Interestingly, the current study showed that the mechanical vibration alone was responsible for a higher expression of collagen I, osteopontin and osteonectin. These results corroborate with previous studies, which showed that the use of mechanical vibration alone is able to induce osteogenic differentiation, although this seems to be greater when an osteogenic medium is used [25,29,33]. Pre, et al. claimed that the use of mechanical vibration alone induces osteogenic differentiation, although a culture medium is favorable to induce bone formation. The authors evaluated the effect of high-frequency vibration on hADSCs in osteogenic and proliferative medium [33]. After 28 days, the highest calcium deposition was showed for cells cultured in osteogenic medium under mechanical stimulation. The statement is supported by Woloszyk, et al. who showed that a higher mineralization process was shown in human dental pulp stem cells under dynamic conditions, and that was even 
more abundant in cultures submitted to both mechanical vibration and osteogenic medium [25]. However, based on findings of the present study, it is not possible to claim whether the use of an osteogenic medium would favor the bone formation, since none comparison was performed considering different medium.

Nonetheless, the hypothesis that the mechanical vibration induces an early differentiation is supported on this study, which showed higher levels of protein expression for the dynamic group after 14 days of culture. According to Pre, et al. the osteogenic differentiation seems to be stimulated on an early stage, decreasing along time after 21 weeks of culture [33]. Considering the short period of analysis from the present study, none prediction could be made regarding the late response of hADSCs.

Likewise, the absence of the expression of osteocalcin in this study is possibly related with the fact that the analysis was performed in 14 days of culture. As osteocalcin is a marker of mature osteogenesis which represents the calcium deposition, it is assumed that its expression could occur on a late-stage differentiation. This statement is supported by previous studies, which showed that the expression of mineralization markers occurs after 14 days of treatment, following the decrease of the proliferation activity $[25,33]$. According to these studies, the mineralization process seems to be higher for stem cells under dynamic conditions, being even more abundant in cultures submitted to both mechanical vibration and osteogenic medium [25,33]. In a previous study, the osteogenic differentiation and mineralization of hADSC using stimulating factors as dexamethasone, vitamin $\mathrm{c}$ and glycerophosphate were shown [11]. In this study, these inducing factors were not added to the culture medium.

Additionally, the low expression of mineralization markers may be related with the absence of differentiation of stem cells into endothelial lineage, which was not evident neither for dynamic conditions nor for the static group. Similar findings were shown for human cells by Jung, et al. on which endothelial lineage on human cells obtained from different types of adipose tissue were weakly expressed [11]. Nonetheless, it is considered that the vascularization of the tissue has an important role on the bone formation. In previous studies, it was showed that the angiogenic differentiation occurs when the stem cells are associated with a culture medium composed with angiogenic factors [34,35]. The bone regeneration requires vascularization and osteogenic factors to initiate bone formation, such as a microenvironment composed by proteins, hormones and growth factors plays an important role on this process [10]. In the study presented by Zhang, et al. the level of mineralization was accompanied by angiogenesis in human adipose-derived stem cells [26].

Adipose-derived stem cells were chosen due to their proliferation capability and osteogenic differentiation potential, such as the acquisition facility by minimally invasive surgical approaches $[10,11,36]$. Although their potential is improved by under dynamic conditions, the association of mechanical vibration with intrinsic factors may be useful to stimulate the angiogenesis and bone formation.

\section{Conclusion}

The mechanical stimulation by means of a bioreactor increased the proliferation and differentiation of hADSCS in comparison to static cultures.

\section{Acknowledgments}

This study was supported by Professor Senninger, the head of the department of Visceral Surgery of the University Hospital Muenster. We also thank QuinXell international $\mathrm{GmbH}$ (Muenster, Germany) for providing the TisXell Regeneration System for this study.

\section{References}

1. Dimitriou R, Jones E, McGonagle D, Giannoudis PV (2011) Bone regeneration: Current concepts and future directions. BMC Med 9: 66.

2. Amini AR, Laurencin CT, Nukavarapu SP (2012) Bone tissue engineering: Recent advances and challenges. Crit Rev Biomed Eng 40: 363-408.

3. Waese EY, Kandel RA, Stanford WL (2008) Application of stem cells in bone repair. Skeletal Radiol 37: 601-608.

4. Salgado AJ, Oliveira JM, Martins A, Teixeira FG, Silva NA, et al. (2013) Tissue engineering and regenerative medicine: Past, present, and future. Int Rev Neurobiol 108: 1-33.

5. Ferretti C, Mattioli-Belmonte M (2014) Periosteum derived stem cells for regenerative medicine proposals: Boosting current knowledge. World J Stem Cells 6: 266-277.

6. Smith BT, Shum J, Wong M, Mikos AG, Young S (2015) Bone tissue engineering challenges in oral \& maxillofacial surgery. Adv Exp Med Biol 881: 57-78.

7. Langer R, Vacanti JP (1993) Tissue engineering. Science 260: 920-926.

8. Declercq HA, De Caluwe T, Krysko O, Bachert C, Cornelissen MJ (2013) Bone grafts engineered from human adipose-derived stem cells in dynamic 3D-environments. Biomaterials 34: 1004-1017.

9. Fischer LJ, Mcllhenny S, Tulenko T, Golesorkhi N, Zhang P, et al. (2009) Endothelial differentiation of adipose-derived stem cells: Effects of endothelial cell growth supplement and shear force. J Surg Res 152: 157-166.

10. Qin Y, Guan J, Zhang C (2014) Mesenchymal stem cells: Mechanisms and role in bone regeneration. Postgrad Med J 90: 643-647.

11. Jung S, Kleineidam B, Kleinheinz J (2015) Regenerative potential of human adipose-derived stromal cells of various origins. J Craniomaxillofac Surg 43: 2144-2151.

12. Samsonraj R, Paradise CR, Dudakovic A, Sen B, Nair AA, et al. (2018) Validation of osteogenic properties of Cytochalasin $D$ by high-resolution RNA-sequencing in mesenchymal stem cells derived from bone marrow and adipose tissues. Stem Cells Dev 27: 1136-1145. 
13. Ramasamy R, Fazekasova H, Lam EW, Soeiro I, Lombard $\mathrm{G}$, et al. (2007) Mesenchymal stem cells inhibit dendritic cell differentiation and function by preventing entry into the cell cycle. Transplantation 83: 71-76.

14. Rahimi M, Zarnani AH, Mobini S, Khorasani S, Darzi M, et al. (2018) Comparative effectiveness of three-dimensional scaffold, differentiation media and co-culture with native cardiomyocytes to trigger in vitro cardiogenic differentiation of menstrual blood and bone marrow stem cells. Biologicals 54: 13-21.

15. Strub M, Keller L, Idoux-Gillet $Y$, Lesot $H$, Clauss $F$, et al. (2018) Bone marrow stromal cells promote innervation of bioengineered teeth. J Dent Res 97: 1152-1159.

16. Zuk PA, Zhu M, Mizuno H, Huang J, Futrell JW, et al. (2001) Multilineage cells from human adipose tissue: Implications for cell-based therapies. Tissue Eng 7: 211-228.

17. Debnath T, Ghosh S, Potlapuvu US, Kona L, Kamaraju SR, et al. (2015) Proliferation and differentiation potential of human adipose-derived stem cells grown on chitosan hydrogel. PLoS One 10: e0120803.

18. Di Taranto G, Cicione C, Visconti G, Isgro MA, Barba M, et al. (2015) Qualitative and quantitative differences of adipose-derived stromal cells from superficial and deep subcutaneous lipoaspirates: A matter of fat. Cytotherapy 17: 1076-1089.

19. Bajek A, Gurtowska N, Olkowska J, Kazmierski L, Maj M, et al. (2016) Adipose-derived stem cells as a tool in cell-based therapies. Arch Immunol Ther Exp (Warsz) 64: 443-454.

20. Hayashi O, Katsube Y, Hirose M, Ohgushi H, Ito H (2008) Comparison of osteogenic ability of rat mesenchymal stem cells from bone marrow, periosteum, and adipose tissue. Calcif Tissue 82: 238-247.

21. Girolamo L, Sartori MF, Albisetti W, Brini AT (2007) Osteogenic differentiation of human adipose-derived stem cells: Comparison of two different inductive media. J Tissue Eng Regen Med 1: 154-157.

22. Cheng NC, Wang S, Young TH (2012) The influence of spheroid formation of human adipose-derived stem cells on chitosan films on stemness and differentiation capabilities. Biomaterials 33: 1748-1758.

23. Choi YK, Cho H, Seo YK, Yoon HH, Park JK (2012) Stimulation of sub-sonic vibration promotes the differentiation of adipose tissue-derived mesenchymal stem cells into neural cells. Life Sci 91: 329-337.

24. Hata M, Naruse K, Ozawa S, Kobayashi Y, Nakamura N, et al. (2013) Mechanical stretch increases the proliferation while inhibiting the osteogenic differentiation in dental pulp stem cells. Tissue Eng Part A 19: 625-633.

25. Woloszyk A, Holsten Dircksen S, Bostanci N, Muller
R, Hofmann S, et al. (2014) Influence of the mechanical environment on the engineering of mineralised tissues using human dental pulp stem cells and silk fibroin scaffolds. PLoS One 9: e111010.

26. Zhang C, Yu L, Liu S, Wang Y (2017) Human amnionderived mesenchymal stem cells promote osteogenic and angiogenic differentiation of human adipose-derived stem cells. PLoS One 12: e0186253.

27. Bancroft GN, Sikavitsas VI, Van den Dolder J, Sheffield TL, Ambrose CG, et al. (2002) Fluid flow increases mineralized matrix deposition in 3D perfusion culture of marrow stromal osteoblasts in a dose-dependent manner. Proc Natl Acad Sci U S A 99: 12600-12605.

28. Ceccarelli G, Bloise N, Vercellino M, Battaglia R, Morgante $\mathrm{L}$, et al. (2013) In vitro osteogenesis of human stem cells by using a three-dimensional perfusion bioreactor culture system: A review. Recent Pat Drug Deliv Formul 7: 29-38.

29. Maredziak M, Lewandowski D, Tomaszewski KA, Kubiak K, Marycz K (2017) The effect of low-magnitude low-frequency vibrations (LMLF) on osteogenic differentiation potential of human adipose derived mesenchymal stem cells. Cell Mol Bioeng 10: 549-562.

30. Bouet G, Cruel M, Laurent C, Vico L, Malaval L, et al. (2015) Validation of an in vitro 3D bone culture model with perfused and mechanically stressed ceramic scaffold. Eur Cell Mater 29: 250-266.

31. Zhang ZY, Teoh SH, Chong WS, Foo TT, Chng YC, et al. (2009) A biaxial rotating bioreactor for the culture of fetal mesenchymal stem cells for bone tissue engineering. Biomaterials 30: 2694-2704.

32. Rosenberg N (2003) The role of the cytoskeleton in mechanotransduction in human osteoblast-like cells. Hum Exp Toxicol 22: 271-274.

33. Pre D, Ceccarelli G, Gastaldi G, Asti A, Saino E, et al. (2011) The differentiation of human adipose-derived stem cells (hASCs) into osteoblasts is promoted by low amplitude, high frequency vibration treatment. Bone 49: 295-303.

34. Konno M, Hamazaki TS, Fukuda S, Tokuhara M, Uchiyama $\mathrm{H}$, et al. (2010) Efficiently differentiating vascular endothelial cells from adipose tissue-derived mesenchymal stem cells in serum-free culture. Biochem Biophys Res Commun 400: 461-465.

35. Bhang SH, Lee S, Shin JY, Lee TJ, Jang HK, et al. (2014) Efficacious and clinically relevant conditioned medium of human adipose-derived stem cells for therapeutic angiogenesis. Mol Ther 22: 862-872.

36. Chen G, Shi X, Sun C, Li M, Zhou Q, et al. (2013) VEGFmediated proliferation of human adipose tissue-derived stem cells. PLoS One 8: e73673. 